\title{
Occupational catastrophe! The digital revolution, global warming, unrest and pandemics: are we prepared?
}

\author{
Joubert, R.W.E. Nat Dip OT (Pretoria College); B A (UNISA); M OT (UDW); PhD (Education) (UDW). \\ http://orcid.org/00-0002-7328-1590 \\ Honorary Associate Professor, Department of Occupational Therapy, School of Health Sciences, University of KwaZulu Natal.
}

Through an extensive scrutiny of relevant print and online media, research publications, global reports and against a participatory occupational justice framework (POJF), the author explores 4 phenomena that are increasingly impacting upon human occupation. They are the $4^{\text {th }}$ industrial revolution with its accelerated technological advancement; global warming and the concomitant climatic changes that are collectively causing human and agricultural displacement with catastrophic side effects; global unrest which is resulting in the displacement and disruption of large numbers of people and the corona virus pandemic with its emerging effects upon so many aspects of human existence.

This is an opinion piece in which the author proposes a potential scenario that will change the face of human occupation and contribute towards considerable threat to the health and wellness of humanity. A scenario in which many occupations will be replaced by advanced technology and/or activities of daily living transformed by climate change. This, together with human displacement, will result in millions of people being jobless and the profile of human occupation changing. The impact of the corona virus remains an emerging phenomenon that is and will continue to have far reaching effects upon human behaviour, occupation, health and the global economy. A further consequence of all these phenomena will provide the world with spiritual, ethical and moral dilemmas that threaten to challenge the training and capabilities of health professionals.

As health professionals with a profound understanding of the physical, mental and spiritual importance of human occupation upon the health of humanity, occupational therapists will need to decide whether or not they are going to react creatively and proactively to these challenges or remain within the boxes of their past.

Guided by the collaborative ethos and enablement skills of the Participatory Occupational Justice Framework (POJF), and current proactive movements within the WFOT and occupational science, the author suggests a tentative approach the occupational therapy profession can adopt in order to contribute to the continuing wellness of humanity and how it may need to transform in order to prepare itself to accost and overcome these challenges.

Key words: Digital revolution, global warming and climate change, global unrest, Pandemics, human displacement, unemployment, occupational chaos and transformation

\section{INTRODUCTION}

This paper is composed as an opinion piece on what the author considers to be four inter-related phenomena that are and continue having a substantial impact upon the transformation of occupational therapy, and if it is to become capable of meeting the future health demands created by these phenomena, we need to take notice. It is therefore written as a provocative piece, and because of the rapidly evolving nature of the phenomena discussed, does not attempt to provide definitive conclusions or solutions but rather to pose possible scenarios that occupational therapists and occupational scientists should, in the author's opinion, take into consideration and research further if we are to plan for, and remain contributors to, the state of health and wellness of our future world.

\section{Modern-day phenomena contributing to a potential occupational catastrophe}

The four phenomena are: the digital revolution; global warming \& climate change; global unrest; and the COVID- 19 pandemic. Never before in the history of occupational therapy have we faced such a challenging future in terms of the changing face and profile of human occupation. The rate of technological advancement in the current digital revolution and the effects of global warming and unrest are occurring at such a rate that it is virtually impossible to keep pace with them. The emerging impact of the corona virus will be with us months or even years into the future and it is also not impossible that other pandemics may emerge more frequently in the future. The effects of these upon our global occupational profile are such that human occupational performance areas and domains as we have come to know and understand them, may be substantially modified within the next decade or two.

This opinion piece will briefly attempt to outline how the impact of these four global phenomena has resulted in the emergence of occupational chaos and related problems which will impact upon the health and quality of life of humanity. In addition - because of the apocalyptic effects of global warming, global unrest and pandemics - these may raise deep spiritual concerns and ethical conflicts that will compound the impact upon the health and wellness and quality of life of humanity!. 
The opinions in this paper were based upon a review and broad thematic analysis of the impact of these phenomena upon human occupation as revealed through relevant journals, media, congressional publications, and backed up with reports from reputable international organisations such as the United Nations Human Rights Commission, World Economic Forum, International Panel on Climate Change, the United Nations International Labour Organisation and WFOT.

A participatory occupational justice (POJ) lens was applied during the analysis wherein the underlying concepts of occupation, enablement, and justice relating to these phenomena were explored against an impending, potentially catastrophic scenario. As such it will require negotiated, collaborative power relations in order to find solutions to it. The POJ framework specifically focuses upon raising consciousness and critical dialogue amongst professionals working in situations that require collective action around issues where there may be occupational injustice ${ }^{2}$.

Based upon this analysis, the author provides some suggestions for how these phenomena will impact human occupational behaviour and probably change the occupational profile of the world to one in which joblessness and related occupational disruption will in turn impact upon the state of wellness and quality of life of humanity. A rapidly emerging future in which millions will be displaced, unemployed, underemployed, intermittently employed and redeployed and many future generations may never be employed in work as we know it today. The potential effects of this upon could become so severe that global collaborative consensus may have to redesign the occupational landscape of the future to provide the necessary occupational incentives and spaces that will reduce health risks and give hope and quality to the lives of the many who will be affected.

\section{The collective consequences of these four phenom- ena upon the occupational profile of the world:}

The author acknowledges the enormous benefits of the digital revolution upon the efficiency and speed of productivity, the outstanding advancement and benefits of health related innovations, and the extraordinary benefits it has had globally in connecting people and allowing substantial work to continue online during pandemic lock downs. However one has to seriously caution an over-optimistic and unbridled approach to this digital revolution. Just as the world once delighted in the discovery of plastic and petrol driven cars, we need to be very cautious about the long term effects of what some digital technology will have upon human occupation, health and spirituality ${ }^{3}$.

Klaus Schwab, founder and executive chairman of the World Economic Forum maintains that the digital revolution will impact not only upon what and how we do things but also upon the very essence of who we are, our identities and issues related to our notions of privacy, ownership, and changes in the patterns of time that we devote to the various activities of daily life we are involved $\mathrm{in}^{4}$.

The United Nations Framework Convention on Climate Change are working towards keeping a global temperature rise to I. 5 degrees Celsius. Life on earth will be seriously compromised should global warming rise above 2 degrees Celsius. According to the International Panel on Climate Change (IPCC) at the current rate of warming, the world could reach a $1.5^{\circ} \mathrm{C}$ increase within the next 10 years. Amongst many other seriously disturbing occurrences, there will be rising sea levels from melting icebergs that will displace millions of people. Human displacement is exacerbated by catastrophic flooding and massive forest and veld fires, which we are experiencing in many parts of the world ${ }^{5}$.

The outcome of these increasingly catastrophic events is that apart from the life threatening trauma they cause, they will also result in substantial emotional trauma through possible loss of loved ones, pets, homes, belongings and jobs. This will have implications for the victims' mental health and occupational habits. The author also anticipates that these factors will create moral and ethical dilemmas related to occupational justice, unprecedented in the history of occupational therapy and occupational science.

Global geopolitical restlessness is increasing due to a complex combination of circumstances related to territorialism and ideological differences, competition for dwindling worldly resources and the greed and reciprocal ego-bruising of powerful narcissistic leaders.

Many refugees who flee the violence and unrest into other countries seek peace and security in asylum in different countries. Frequently additional tensions and exploitation arise between the refugees and their host country because they pose a threat to already strained resources and job opportunities within host countries. South Africa is already experiencing the unpleasant consequences of Xenophobia that have arisen since an influx of refugees from other African countries.

As this article goes to press, we are still in the midst of the COVID-19 pandemic and because of its novelty, uncertainty remains about what the ultimate duration and consequences of it will be. The global upheaval has, according to the United Nations, resulted in a human, economic and social crisis ${ }^{6}$ of which the longterm effects upon humanity are currently unquantifiable with regard to employment, the world economy and health.

On a positive note the temporary periods of prolonged lockdown, appear to have demonstrated beneficial effects globally upon the reduction of carbon emissions which has provided some respite for our suffocating world and perhaps slightly slowed down the speed of global warming for the moment.

The disruption to routine in essential healthcare services to make way for the COVID-19 onslaught has impacted negatively on the provision of general health care in South Africa ${ }^{7}$. In addition, providing a compassionate and holistic service within an enforced sterile environment is seriously restrictive and must impact negatively upon occupational therapy interventions particularly for children and institutionalised people with disabilities. However this paper will not discuss how these aspects of COVID-19 impact occupational therapy delivery but will rather focus upon the long-term implications it has for human occupation and in particular work, and how it has and may continue to impact specifically upon mental health, spirituality and quality of life, and the ramifications of these for our transforming role as occupational therapists.

The following are examples of the impact of these phenomena:

- They are reshaping the traditional size and structure of employment.

While new jobs will be created through digital technology, in its wake many jobs (especially routine, repetitive jobs), have largely been taken over by robots and computers resulting in substantial unemployment figures ${ }^{8}$. The Mckinsey report (2019) on the loss and gain of jobs in USA, estimated that $14 \%$ ( 375 million) of the global workforce may need to transition to new occupational categories and learn new skills. This report further suggests that by 2030 the occupational categories of approximately $40 \%$ of Americans will shrink?

Some sources suggest that in the near future, $50 \%$ or more of 
current jobs could become obsolete ${ }^{10}$. The International Labour Organisation (ILO) in its trends for 2020 predicts that shortage of jobs and labour underutilisation are likely to continue into the future. Their report also recognises the inequalities prevailing in the labour market where, in some low-income countries, unemployment rates are much higher. Perhaps one of the most concerning finding was that there are approximately 267 million young people aged between 15 and 24 worldwide who are not in any employment, education or training" .

The multiple impact of climate change resulting in agricultural displacement due to rising oceans, desertification, deforestation, pollution, droughts, fires and flooding - will cause substantial reduction in livestock and crop production and marine fisheries further threatening job and food security ${ }^{5}$. The March 2020 United Nations Climate report maintains that this will have knock-on effects upon socio-economic development, human health, migration and displacement, and food security ${ }^{12}$.

At the end of 2018, the United Nations Human Rights Commission on Refugees ${ }^{13}$ reported 70.8 million people worldwide who had been forcibly displaced as a result of persecution, conflict, violence or human rights violations, and many of these include women and children. It is not difficult to imagine the impact this must have upon occupational disruption and quality of life.

The ILO also noted that before COVID- 19 spread worldwide, global unemployment already stood at around 190 million. The latest assessment reflects that full or partial lockdown measures affected almost 2.7 billion workers (four in five of the world's workforce) and that millions could become unemployed $^{14}$. As a result there will be rapidly intensifying economic effects upon the world of work and these effects appear to be far worse than any previous financial crisis.

Research from the World Economic Forum (WEF) estimates that $42 \%$ of the pandemic lay-offs will experience permanent job loss and in the long term COVID-19 will have profound consequences with regard to the reallocation of jobs, workers, and capital across firms and locations and that people with the lowest incomes are the most vulnerable to job loss ${ }^{15}$.

A South African National Income Dynamics Study - Coronavirus Rapid Mobile Survey (Nids - Cram) in July 2020, revealed that three million jobs were lost after the first month of lockdown. In addition employment has declined substantially and the effects of this are most significant for the most disadvantaged, particularly the poor and women ${ }^{16}$.

In view of this it is unlikely that we will ever be able to create enough jobs for all those eligible for them in future. It is also likely that work will progressively become scarcer so that millions of people may never experience work as we know it. The general time frames for our daily activity clocks may continue to change with the prospect of leaving millions with days in which there will be long periods of available time during the day that would otherwise have been filled with work related activities. Such conditions can contribute to a sense of hopelessness and are likely to impact upon quality of life.

\section{- Upskilling of existing workers and skills development of} emerging workers to new types of work.

Although some jobs are dying there are also new ones emerging. In addition to this, in comparatively low socio-economic countries, there are established and emergent occupations that need to be factored into new classifications of occupations. For example in many low economy countries, we have a category of workers referred to as 'waste collectors/pickers'. They have emerged out of a world of poverty to become opportunistic collectors of recyclable waste such as tin, glass, metal and paper for which they get paid. Their role is symbiotically important in not only providing an income but also in providing a proactive solution to the growing problems of pollution our world faces.

\section{- There are changes in the traditional time, infrastructure,} and site of work.

The corporate world is transforming into "pop-up" businesses that are powered by what is known as "gig workers" who are employed on a free-lance basis for a particular performance or a defined time, with very little or limited connection to the site of employment ${ }^{17}$. Duszynski ${ }^{18}$ maintains that in a post-pandemic world, many job seekers will look towards the gig economy for answers to unemployment. During the Covid pandemic businesses have had to rethink their work places and spaces. Statistics South Africa ${ }^{19}$ revealed in a survey conducted between April and May 2020 that nearly $78 \%$ of its respondents who worked during the lockdown, did so from home. Given the beneficial effects of the dramatic reduction in travel and thus carbon emissions during lockdown, future efforts to control carbon emissions may suggest that in future more people work from home and thus a whole new approach to occupational spaces and the delivery of certain categories of work.

\section{- There are challenges affecting interpersonal relationships} and the spiritual, moral and ethical integrity of humanity. We have yet to fully unpack and comprehend the impact of social media and virtual reality upon the total health of the world, with its quick and largely superficial gratification, and addictive influence. Research indicates that individuals suffering from this addiction demonstrate an irrational, compulsive and excessive use of social media resulting in the affected person manifesting mood changes such as anxiety, and depression, stress, low self-esteem and cognitive problems that may result in reduced academic performance ${ }^{20}$.

Health professionals should also question how this impacts on the physical, mental and spiritual integrity of those concerned, when their addiction results in a mostly inert, indoor and sedentary lifestyle.

- Interactive digital technology and social media provides essential interpersonal communication during times such as pandemics, where people may become isolated or separated from one another.

During the COVID-I 9 pandemic, interactive technology, social media and live streaming digital options were able to provide essential communicative resources for many in lockdown situations who would otherwise have been seriously isolated and cut off from family, educational and religious institutions and work. However, for all its advantages this resource still raises serious ethical concerns regarding equity, especially in low income countries such as South Africa, where disadvantaged learners and students may have inadequate access to the internet and the appropriate digital technologies.

\section{- There will be effects upon mental health.}

The combined effects of fear, isolation, uncertainty, hopelessness and related stressors that these phenomena cause, create a breeding ground for substantial and long-term 
mental health disorders.

The victims of extreme weather calamities and global unrest are often left bereft of their livelihoods, identities, relationships and memories, facing uprooted lives ${ }^{21}$. The impact of this upon their physical, psychological and spiritual well-being, with toxic stress, post-traumatic stress disorder, major depressive disorder and generalised anxiety disorders being common problems, recorded under such circumstances ${ }^{13,21,22}$. These are similar to those experienced by people quarantined under lockdowns and pandemics which includes other aspects such as insomnia, irritability, emotional exhaustion, boredom, anger, frustration and mood disorders that endure in some for months after quarantine $^{23}$. Problems related to mental health are arguably the most important contributors to the burden of disease and disability throughout the world and constitute a substantial portion of global disability statistics ${ }^{24}$.

\section{- Effects upon spirituality.}

In times when the global sustainability of humanity is threatened by climatic and unrest conditions, combined with a pandemic over all of which we have very little control, it is common for us to turn to what we consider as a higher power or God, and prayer, as a means to help us cope with our vulnerability. From an African perspective this pandemic has also highlighted the consequences as they relate to the concept of Ubuntu in which our inter-relatedness and interdependence upon one another is inseparable, but ironically in which this very interdependence has become life threatening in terms of what our contact with each other can mean should we become infected.

In addition to this, under the pandemic the ability to come together in churches, temples, synagogues, mosques and other places of worship has been banned in many parts of the world, prohibiting millions from accessing an important source of spiritual nutrition.

Positively, this weird situation in some instances has brought about a global united front to a common invisible enemy, resulting in unprecedented acts of altruism from those who are less affected towards those who have been adversely affected. And ultimately a rekindling of faith in many people who previously did not find solace in placing their destiny at the feet of a higher power. Such changes in humanity could be positively harnessed in any new endeavours to deal with the crises that are likely to follow the current situation.

\section{- A changing morality and socio-economic altruism?}

The current state of the world on almost every level, spells out serious consequences for all living creatures of the future. Humanity has historically shown a propensity for placing more importance on accumulating material wealth at the expense of the health of environment and humanity. When 20 people own the same amount of wealth as 3.8 billion people who make up the poorest in the world ${ }^{25}$, then something is very wrong with the morality of our world. As the potential for natural disasters, pandemics and unrest heightens, humanity will have to become much more altruistic in terms of how we care for one another and thus also how we spread our wealth. Spurred on by the positive altruistic reactions to the COVID-19 pandemic this paper will optimistically assume that there will be an increasing global scenario of altruism and stewardship which will influence how we as occupational therapists contribute to finding solutions and interventions to the challenges created by these phenomena.
The COVID- I 9 Pandemic and global warming have ironically created the perfect conditions for humanity to be galvanised into an anxious reflection upon priorities related to health and survival versus material wealth. One of the positive possibilities emerging from this is that it may well become the catalyst as to how we transform the global economic distribution to create a more equitable world and how we can unify and collaborate as a global family to find solutions to life threatening and health related problems. Occupational therapy and occupational science have an important place in participating in the appropriate transformation platforms.

\section{What is the role of occupational therapy?}

The essence of our humanness lies in our daily engagement in occupation and it is within this 'doing' of occupation as Wilcock ${ }^{26}$ puts it, that we find our 'being' which includes our spiritual being, we feel that we 'belong' and ultimately we 'become' our identity within our communities and world. Each one of these components is essential to being holistically healthy. According to Whalley Hammel ${ }^{27}$ the priorities for human well-being of the majority of the world's peoples are: belonging, connectedness and interdependence which echo's with Wilcock. The preceding scenario suggests several rhetorical questions:

How can and does occupational therapy, through occupational science, respond to millions of hopeless, displaced and jobless people where a large proportion of the time used for their previous daily work occupations has become a vacuum? How do we transform human occupational opportunity to rebuild a sense of hope and meaning to disrupted lives?

Should occupational therapy be concerned about, and respond to the effects of whether and how a digitally loaded and often disrupted world may have negative impacts upon the totality of psyche, body and spirit that makes us occupational beings? A humanity whose brains, bodies and spirits are being rewired to adapt to this virtual, synthetic and accelerated existence? A humanity where many adults and children are becoming so caught up in the addiction of this technology that it is changing the very nature of how we interact with one another and with our natural world. How does this effect the holistic development of children and the connectedness and spirituality of children and adults?

Do we have a role to play in the future of this occupationally transforming world which raises many questions related to occupational justice? The World Federation of Occupational Therapists (WFOT) and related organisations have been very proactive in creating a resource manual and other literature on occupational therapy for displaced people which is a positive start to what should become an ongoing and evolving quest to ensure that we play our part in contributing to these challenges ${ }^{21,28,29,30}$.

WFOT ${ }^{31}$, in its definition of occupational therapy, emphasises a human centred focus upon health and well-being which is brought about through humanity's essential engagement in occupation. Its primary goal being to enable us, to be able to participate freely in the everyday activities and occupations of life. This can only be achieved by working collaboratively with people and communities and governments to "enhance peoples (sic) ability to engage in the occupations they want to, need to, or are expected to do, or by modifying the occupation or the environment to better support their occupational engagement" $31: 1$. Thus any situation or circumstance that threatens the health and well-being of humanity globally by negatively impacting upon our ability to freely engage in some, or all the occupations of everyday life, requires a particular alertness 
and vigilance on the part of the occupational therapy profession and occupational science as to how it will impact occupational justice.

The WFOT definition of occupational therapy implies a consensus about the importance of our role in this future, but now we have to decide exactly what that role will be. It will certainly expand from the existing roles of largely institution-based and disability focussed interventions. It will need to redirect focus from individual and small groups to large groups of people and communities. It is also likely that the focus will be on prevention of health related consequences and the promotion of, as yet, newly emerging occupational lifestyles that enhance quality of life. I am not suggesting that we will ever digress from our original important role within a remedial, rehabilitation and disability focus, but that we will have to consider specialisations that go beyond the traditional boundaries into a new arena, some of which are evolving as I write ${ }^{21,28,29,30}$.

Most of it will have to be carefully and incrementally designed in consultation with appropriate role players and stakeholders. And certainly planning and defining the new role will require interdisciplinary and inter-sectoral collaboration. Surviving this catastrophe requires a global collaborative effort and participatory approach ${ }^{27,2}$ in a process of identifying, creating and implementing occupational opportunities, projects and spaces that would accommodate the needs of those affected.

Rushford ${ }^{29}$ refers to an 'occupational stewardship' which positions occupation as a transformative medium in change, a socioecological process of engagement which is closely related to the protection, preservation and management of natural resources and the wellbeing of the world populations. This stewardship process also requires ongoing collaboration within both governmental and non-governmental organisations worldwide.

As implied above, in order for the profession to survive we must expand our role and scope of practise and diversify but in doing so, we must never lose the essence of what occupational therapy stands for, the core belief inextricably woven into our ethos, that links people as occupational beings to health and wellness ${ }^{21}$ and particularly those made more vulnerable through disability or impending disability.

Research is already revealing how people's involvement in nonwork occupations (and programmes) creates a sense of belonging and allows people in the absence of employment to retain their social and personal identities and a sense of inclusion. If we are to address meaningful occupational programmes, we should include occupations that are concerned with belonging, connecting, and contributing to others ${ }^{30}$ and our environment.

What follows are some speculative suggestions of principles that should be inherent in future transformative discussions. They are by no means exhaustive.

\section{Principles underlying occupational therapy involve- ment and interventions:}

- At all times ensuring implementation of the basic principle that occupational rights are human rights (WFOT) ${ }^{31}$.

- Applying an ethos of occupational stewardship and collaborative engagement ${ }^{29}$ which requires careful and responsible management of the well-being of the populations at risk. It requires an ethical approach which is particularly associated with environmental protection, preservation and natural resource management thus an eco-orientation to occupational transformation is essential.

- Using a Participatory Occupational Justice Framework ${ }^{2}$ approach which ties in with that of stewardship and collaborative engagement. This means striving towards a situation in which all populations have the opportunities, resources, privilege and right to participate in their desired occupations and achieve their potential within such occupations. It emphasises community development and population approaches, occupational participation, and ongoing vigilance to power and inequity in everyday life.

- It requires a critical or radical practice approach which focuses on transforming and influencing regulations, policies, laws, economic practices, media images, professional practices, and those forces that determine what people can and want to do, through collaborative means. It raises ethical, moral, civic, and philosophic questions about injustice and the tensions or gaps between ideals and the reality of communities or populations living everyday with inequitable disadvantages or oppression associated with natural disasters or avaricious societies ${ }^{2,31}$.

- Designed projects have to contribute to the betterment of the affected individuals, societies and communities. They should be sustainable and preferably provide incentives.

- Because of its evolving nature this process will require reflective practice and constant evaluation and adaptation of and to the efficacy of interventions ${ }^{2,22}$.

\section{Suggested roles of Occupational therapists and Occupational Scientists:}

- Providing consultative services to relevant role players regarding the planning, structure, and content of occupational programmes and spaces to accommodate the anticipated increase in the numbers of unemployed, partially employed, quarantined and displaced individuals. This may include health services, communities, appropriate professional groups, organisations, and relevant government and non-governmental organisations ${ }^{21}$.

- Working together with various role players and professions in identifying at risk populations in order to create appropriate occupational spaces. These could accommodate at risk populations within meaningful, contributory occupational programmes and opportunities that will enhance societal upliftment. It essentially requires the development of transcultural, holistic and community centred interventions in which occupational therapists work together with those affected, as social activists fighting for the necessary occupational justice ${ }^{27}$.

- Working together with religious and spiritual role players to provide opportunity for the nurturement and sustainability of spirituality.

Statistics ${ }^{32}$ for 2018 revealed that approximately $84 \%$ of the world's population ascribe to one or other religious belief system and only $16 \%$ do not. The essence of the major world religions revolves around compassion and service to mankind and respect for God's creation. How we serve mankind not only requires our involvement in various occupations, but by these very acts contributes towards the process of becoming more human.

From its birth, occupational therapy has emphasised its belief on the holistic nature of humanity. Way back in the 1960s, Du Toit ${ }^{33}$ based her model of Creative Ability upon the belief that 'man' is a totality of psyche (mind), soma (body) and spirit. That all these components interact upon, and together with one another, such that this interaction and diffusion, ultimately constitutes what the person is and becomes within their particular context.

Occupational therapy has in the last 20 odd years debated the place of human spirituality within our role and scope. Arguably this process is still open for discussion. However the author maintains 
that if we consider humans as a totality of body, mind and spirit, but we fail to adequately articulate the link between human occupation and spirituality, then we are only responding to two thirds of the human condition and, as such, we negate the holistic nature of that totality. Our existing philosophy tends to emphasise humanism in our consideration of the occupational nature of humanity but it often excludes the importance of theism as it relates to spirituality and its influence upon how humanity uses occupation to contribute to the wellness of each other and our world.

\section{CONCLUSIONS}

The author has attempted to sketch the outline of an enormously complex potential for occupational catastrophe which is occurring at a speed that is almost impossible to keep up with. Because there are so many similar occupational challenges within the four major phenomena discussed in this paper, more research into these would be an essential step forward.

It is not a question of whether this anticipated occupational catastrophe will happen, it is already happening, it is now a question of what we can do to lessen the impact. As a profession we cannot waste time. Leaders and protagonists in occupational therapy and occupational science, through their own associations and WFOT, need to come together to form a global advisory board and, using existing evidence, to strategise ways of prioritising the related problems, restructuring the occupational therapy curriculum and redefining our role and scope in order to include essential knowledge that will equip us to meet these challenges and the prolonged uncertainty they pose to the mental, physical and spiritual health of humanity. Essentially this will require that we are not simply agents and advocates for occupational justice but, where and when necessary, we also become, activists.

\section{REFERENCES}

I. Joubert, Robin. Global occupational transformation, in a technologically, climatically and politically changing future: where to occupational therapy. (Podium presentation) WFOT Congress, 21 - 25 May 2018, Cape Town.

2. Whiteford G, \& Townsend E. Participatory Occupational Justice Framework (POJF): enabling occupational participation and inclusion. In Kronenberg,F.Pollard,N.\& Dikaios,S. (Editors) Occupational Therapies Without Borders: Volume 2. Churchill Livingstone (Elsevier), Edinburgh; $20 \mathrm{II}$. https://doi.org/10.1016/B978-0-7020-3103-8.00017-I

3. Joubert Robin. An Anticipated Global Occupational Chaos of the Future: How can the Vona du Toit Model of Creative Ability Contribute to Solutions? (Podium presentation).6th ICAN International Vona du Toit Model of Creative Ability Conference, London; 24th June 2019. London

4. Schwab, K. The Fourth Industrial Revolution.

https://www.weforum.org/about/the-fourth-industrial-revolutionby-klaus-schwab 25/04/18

5. IPCC International Panel on Climate Change October 2018 Summary for Policymakers of IPCC Special Report on Global Warming of $1.5^{\circ} \mathrm{C}$ approved by Governments; 2018. https://www.ipcc. $\mathrm{ch} / 2018 / 10 / 08 /$ summary-for-policymakers-of-ipcc-special-reporton-global-warming-of-I-5c-approved-by-governments/ (25/09/19)

6. United Nations. "Everyone included" The Social impact of COVID-19.

7. ASSAf Standing Committee on Health: Covid-19 Statement; 2 July 2020.

8. McKinsey Global institute: Jobs lost, Jobs Gained, workplace changes in a time of Automation; December 2017. https://www.mckinsey. com/ /media/McKinsey/Featured\%20Insights/Future\%20of\%20 Organizations/What\%20the\%20future\%20of\%20work\%20 will\%20mean\%20for\%20jobs\%20skills\%20and\%20wages/MGIJobs-Lost-Jobs-Gained-Report-December-6-20I7.ashx

9. The McKinsey Global Institute, The Future of Work in America: People places today and tomorrow; July 2019. https://www.mckinsey. com/ /media/McKinsey/Featured\%20Insights/Future\%20of\%20Organizations/The\%20future\%20of\%20work\%20in\%20America\%20 People\%20and\%20places\%20today\%20and\%20tomorrow/MGIThe-Future-of-Work-in-America-Report-July-20I9.ashx

10. Jensen \& Kock. Man and Machine: Robots on the rise. The impact of automation on the Swiss job market. Deloitte; 2015.

https://www2.deloitte.com/ch/en/pages/innovation/articles/ automation-report.html (20/05//8).

II. The International Labour Organisation. World Unemployment and Social Outlook: trends. International Labour Office - Geneva: ILO, 2020. ISBN 978-92-2-03I408-I https://www.ilo.org/wcmsp5/groups/public/---dgreports/--dcomm/---publ/documents/publication/wcms_734455.pdf

12. The WMO Statement on the State of the Global Climate in 2019 -UN weather agency (World Meteorological Organization). https://library.wmo.int/doc_num.php?explnum_id=1021 I

13. United Nations Human Rights Commission, Review: Global Trends, Forced Displacements in 2018. https://www.unhcr.org/globaltrends2018/

14. United Nations News - COVID-19: impact could cause equivalent of 195 million job losses; 8th April 2020. https://news.un.org/en/story/2020/04/106/322

15. The World Economic Forum COVID Action Platform. https://www.weforum.org/agenda/2020/05/42-of-jobs-lost-duringcovid-19-may-not-come-back/

16. NIDS CRAM 2020 Coronavirus Rapid Mobile Survey: an overview of results and findings By NIDS-CRAM Researchers • I 5 July 2020 https://www.dailymaverick.co.za/article/2020-07-I5-overviewchapter-of-the-2020-coronavirus-rapid-mobile-survey-results-andfindings/\#gsc.tab=0

17. Danaher M. Have you heard the term "gig workers" yet? You will. Posted on December 20, 2015.

https://www.employmentlawmatters.net/20I5/I2/articles/flsa/ have-you-heard-the-term-gig-workers-yet-you-will/

18. Duszynski M. Gig Economy: Definition, Statistics \& Trends (2020 Update). https://zety.com/blog/gig-economy-statistics

19. COVID-19 severely impacts employment. South African Government News Agency, May 20, 2020.

https://www.sanews.gov.za/south-africa/covid-19-severelyimpacts-employment

20. Hou Y. Xiong D. Jiang T., Song L., \& Wang Q. (20I9). Social media addiction: Its impact, mediation, and intervention. Cyberpsychology: Journal of Psychosocial Research on Cyberspace. 2019; I3(I): article 4. http://dx.doi.org/I0.58I 7/CP20I9-I-4 (I8/08/I9)

21. Resource Manual: Occupational Therapy for Displaced Persons. World Federation of Occupational Therapists; 2019.

22. Campbell E.J. \& Turpin M.J. Refugee settlement workers' perspectives on home safety issues for people from refugee backgrounds. Australian Occupational Therapy Journal. 2010; 57(6): 425 - 30. http://doi.org/10.1 II I/j.1440-1630.2010.00882.x

23. Brooks S.K, Webster R.K, Smith L.E. Woodland L, Wessely S, Greenberg N, Rubin G.J. The psychological impact of quarantine and how to reduce it: rapid review of the evidence. Lancet. 2020; 395: 912 - 20. Published Online February 26, 2020 https://doi.org/10.1016/S0 I40-6736(20)30460-8 
24. Phehlukwayo S.M. (2019) Exploration of Care Coordination Needs for Chronic Mental Illness. Care in a District Health System. Seminar presentation Vocational Rehabilitation. 16th May 2019. Department of Occupational Therapy. University of KwaZulu Natal.

25. Barolini A. The poor keep getting poorer and the rich richer. Lifegate: World Inequality Report; 2018. https://www.lifegate.com/people/news/world-inequality-report-2018

26. Wilcock, A. Occupation and Health: Are they one and the same thing? Journal of Occupational Science. 2007; 14(I): 3 - 8.

https://doi.org//0.1080/14427591.2007.9686577

27. Whalley Hammel, K.(20I4). Belonging, occupation, and human wellbeing: An exploration. Canadian Journal of Occupational Therapy. Vol 8I (I): 39-50.

https://doi.org//0.1 177/0008417413520489

28. Rushford N. \& Thomas K. Disaster and development: An Ocupational Perspective. London: WFOT. Elsevier; 2015.

29. Rushford N. (20I5). Chapter 3I, Occupational Stewardship and Collaborative Engagement: A Practice Model. In Rushford N. \& Thomas K. (editors) Disaster and development: An Occupational Perspective. WFOT, Elsevier; London.

30. Algado, S. \& Cardona,C. The return of the corn men: an intervention with a Mayan community of Guatamalan retornos. In Kronnenberg, F, Algado,S and Pollard,N. (Editors). Occupational Therapy without borders: learning from the spirit of survivors. Edinburgh: Elsevier Churchill Livingstone; 2005.

31. WFOT 2012. Website https://www.wfot.org/about-occupational-therapy (12/09/19).

32. Age of the Sage.org. Major world religions populations' pie-chart. (2019) https://www.age-of-the-sage.org/mysticism/world_religions_populations.htmll

33. Du Toit, H.J.V.(1962) Initiative in Occupational Therapy. In Patient Volition and Action in Occupational Therapy. Vona \& Marie du Toit Foundation. University of Pretoria, South Africa; 2004.

\section{Corresponding Author}

\section{*Robin Joubert}

Email: joubertr@ukzn.ac.za 